\title{
Validation of the Turkish Translation of the Facial Clinimetric Evaluation Scale in Patients with Peripheral Facial Paralysis
}

\author{
Ağah Yeniçeri ${ }^{1}$ (D) Fakih Cihat Eravcı ${ }^{2}$ (D), Mücahit Yalçın³ ${ }^{3}$, Hakan Tutar $^{3}$ (D) \\ ${ }^{1}$ Ministry of Health Kırsehir Education and Research Hospital, Department of Otorhinolaryngology, Kırşehir, Turkey \\ ${ }^{2}$ Necmettin Erbakan University, Meram Medical Faculty, Department of Otorhinolaryngology, Konya, Turkey \\ ${ }^{3}$ Gazi University, Faculty of Medicine, Department of Otorhinolaryngology, Ankara, Turkey
}

ORCID ID: A.G. 0000-0002-5024-4009; F.C.E. 0000-0001-9092-7923; M.Y. 0000-0002-2083-1827; H.T. 0000-0001-5585-5282

Citation: Yeniceri A, Eravci FC, Yalcin M, Tutar H. Validation of the Turkish translation of the facial clinimetric evaluation scale in patients with peripheral facial paralysis Tr-ENT 2021;31(2):45-50. https://doi.org/10.26650/Tr-ENT.2021.952546

\begin{abstract}
Objective: To transcribe and validate the Facial Clinimetric Evaluation (FaCE) scale to be able to use it in a Turkish-speaking patient population with peripheral facial paralysis (PFP).

Material and Methods: The original English FaCE scale was translated according to international guidelines. Then a validation study was conducted on 37 patients with facial paralysis. The patients completed the scale twice at a 1-week interval. Internal consistency was evaluated with the Cronbach alpha coefficient. The correlations between the FaCE scale and the House-Brackmann Grading System (HBGS), the Sunnybrook Grading System (SBGS), and the Facial Disability Index (FDI) scores and structure validity were evaluated by calculating the Spearman rho correlation coefficient.

Results: The FaCE scale showed internal consistency with an excellent Cronbach $\alpha$ value of 0.828 . Test-retest reliability was shown with an Intraclass Correlation Coefficient (ICC) in the range of 0.51-0.95. The FaCE scale was determined to be well correlated with the HBGS and SBGS points ( $r=-0.51, r=0.65$, respectively). The FaCE scale face movement score showed the highest correlation with HBGS ( $r=-0.61)$. SBGS had the highest correlation with the oral function score $(r=0.61)$. The study determined there to be a good correlation between the FaCE scale and the social/well-being function and physical function of the FDI ( $r=0.69, r=0.66$, respectively).

Conclusion: The FaCE scale is a reliable and valid tool for assessing the quality of life of PFP patients. The Turkısh version of the FaCE Scale showed good psychometric properties. By showing high validity and reliability, the Turkish FaCE scale can be used in Turkish-speaking patients with peripheral facial paralysis.
\end{abstract}

Keywords: Translation, facial clinimetric evaluation scale, validation, quality of life, facial paralysis

\section{INTRODUCTION}

Peripheral facial paralysis (PFP), most frequently seen as idiopathic, is paralysis of the facial nerve that develops associated with infection, trauma, malignancy and iatrogenic etiological causes (1). The annual incidence of PFP in the general population varies between 20 and 32 per 100.000 (2). Different treatment methods can be used for the elimination of functional problems in PFP, primarily corticosteroids, antivirals (ac iclovir) and surgery $(1,2)$.

Patients with facial paralysis may have symptoms such as facial asymmetry, weakness of facial muscles, inability to fully close the eyes with associated ophthalmic injuries, difficulties in eating, drinking, and talking, reduced sense of taste, and synkinesis. In addition to these functional problems, a series of psychosocial outcomes such as social isolation and depression can emerge with PFP (3). Therefore, to be able to comprehensively evaluate patients with facial paralysis, the psychosocial status and the effect of that on quality of life (QoL) must be taken into consideration together with functional problems.

It is difficult to evaluate QoL in PFP patients. Currently, there is confusion related to clinician-based scales evaluating QoL

Corresponding Author: Ağah Yeniçeri E-mail: agah_yeniceri@hotmail.com

Submitted: $16.06 .2021 \bullet$ Accepted: 05.08.2021

This work is licensed under Creative Commons Attribution-NonCommercial 4.0 International License. 
and several patient-based evaluation scales. Of these, the House-Brackmann Grading System (HBGS) and the Sunnybrook Facial Grading System (SBGS) are the most used clinicianbased evaluation systems $(4,5)$. Although these determine the anatomic and physiological severity of facial paralysis (3), they do not consider the effect of PFP on QoL. The Facial Clinimetric Evaluation Scale (FaCE) (6) and the Facial Disability Index (FDI) (7), which are used for the evaluation of QoL in PFP patients, are patient-based QoL scales which are well known by clinicians, easy to use, and have proven validity and reliability $(8,9)$. Since they were first created, these scales have been used in many international clinical studies $(3,8-10)$.

The FDI provides an evaluation of the feelings about the mouth, eyes and other facial features, and the effects of these on QoL (7). The FaCE scale includes 15 questions. The 6 subdimensions comprise facial movements, social function, facial comfort, lacrimal control, eye comfort, and oral function. The total points and affected area points range from 0 (worst) to 100 (best) (6).

Following use of the original English versions, the FaCE and FDI scales have been translated and approved for use in several languages, such as French, Spanish, Italian, German, Chinese, Dutch, and Swedish (11-17). Only the FDI has been translated and approved in the Turkish language (18). The purpose of this study was to form and validate the Turkish model of the FaCE scale for a Turkish-speaking population.

\section{MATERIALS AND METHODS}

\section{Ethics}

The study was approved by the Ethics Working Group for Scale Evaluation of Gazi University (Approval no: 2019-361). We obtained permission for this study by interviewing the authors of the English original of the FaCE scale. This study was conducted in two stages, first as a pilot study with the translation of the FaCE scale from English to Turkish, then in the second stage as validation in a PFP patient community.

\section{Translation}

The translation process was implemented according to the internationally accepted recommendations for the translation and cross-cultural adaptation of health-related quality of life scales $(19,20)$. The original English FaCE scale was translated into Turkish independently by two ear, nose, and throat specialists, both of whom were native Turkish speakers and had an excellent level of English. Then the two versions were examined by a committee that was participating in the study, and consensus was reached. The Turkish model was then independently translated back into English by two English native-speaker translators, both of whom had an excellent level of Turkish. The aim of this back-translation was to determine any differences in consistency and context between the original model and the back-translated Turkish version. A professional medical translator then compared the back translations with the original English FaCE. As a result of this, there were no differences in meaning or any inconsistency detected, and the
Turkish version of the FaCE was approved. Finally, a pilot test was conducted on 5 patients with PFP and 5 healthy individuals, all of whom were native Turkish speakers. These 10 subjects completed the Turkish version of FaCE under the supervision of one of the researchers. No differences or problems were determined in respect of reading, understanding or responding to the scale items, and so no changes were made to the Turkish version of the FaCE scale.

\section{Questionnaires}

The FDI, developed by Van Swearingen et al in 1996, is a QoL scale (7), which was translated into Turkish in 2020 (18). It consists of two areas, social/well-being function and physical function. It contains 10 Likert type questions in total. The social/well-being function points interval from 0 (worst) to 100 (best) and the physical function points interval from -25 (worst) to 100 (best).

The FaCE scale, developed by Khan et al in 2001, is a PFPrelated QoL scale (6). It includes 15 items with responses on a 5-point Likert scale, in 6 sub-dimensions: facial movements, social function, facial comfort, lacrimal control, eye comfort, and oral function. The total points and affected area points range from 0 (worst) to 100 (best) (6).

\section{Validation}

This study was conducted with 37 patients with PFP in the Ear, Nose, and Throat (ENT) Clinic of Gazi University Medical Faculty Hospital between November 2019 and June 2020. The patients included were aged $>18$ years, were able to read and write in Turkish, and had a diagnosis of unilateral PFP ongoing for at least 3 months. Patients were not included from the study if they had poor cognitive functions, were illiterate, had temporary PFP (Bell's Palsy), bilateral facial paralysis or if they refused to sign the consent form.

Demographic data of the patients such as age, gender, etiology, and duration of paralysis were obtained from the patient and hospital medical records. The severity of PFP was evaluated with the HBGS and SBGS $(4,5)$. HBGS is a clinician-based system that evaluates facial function, in which PFP is graded from I (normal) to IV (total paralysis) (4). The SBGS is a system which evaluates symmetry at rest, involuntary movement symmetry, and synkinesis. At the end of the evaluation, a total point is determined through comparison with the normal side, ranging from 0 (total paralysis) to 100 (normal function) (5).

All the patients included in the study provided signed informed consent. The patients completed the Turkish FaCE scale and FDI. For test-re test reliability, the same patients completed the FaCE scale again after a 1-week interval. During that period of one week, no treatment was applied to the patients.

\section{Statistical analysis}

Statistical analysis was performed using the software program SPSS version 22.0 for Windows (IBM Corp. Armonk, NY). Descriptive statistics were analyzed to identify patient characteristics. Correlations between the Turkish FaCE scale 
Table 1: Patient Characteristics.

\begin{tabular}{|c|c|c|c|c|c|c|c|}
\hline Patient Characteristic & & $\mathbf{N}$ & $\%$ & Mean & SD & Median & Range \\
\hline \multirow[t]{2}{*}{ Gender } & Female & 13 & 35.1 & & & & \\
\hline & Male & 24 & 64.9 & & & & \\
\hline Age (years) & & & & 47.35 & 16.104 & 52 & $18-70$ \\
\hline \multirow[t]{2}{*}{ Side } & Left & 18 & 48.6 & & & & \\
\hline & Right & 19 & 51.4 & & & & \\
\hline Duration of PFP (months) & & & & 85.84 & 105.812 & 60 & $3-480$ \\
\hline \multirow[t]{5}{*}{ Etiology } & Acoustic neuroma & 10 & 27.0 & & & & \\
\hline & Trauma & 5 & 13.6 & & & & \\
\hline & latrogenic & 6 & 16.2 & & & & \\
\hline & Tumors & 6 & 16.2 & & & & \\
\hline & Other & 10 & 27.0 & & & & \\
\hline HBGS & & & & 4.16 & 1.191 & 5 & $2-6$ \\
\hline SBGS & & & & 35.84 & 18.811 & 30 & $9-91$ \\
\hline
\end{tabular}

SD: Standard Deviation, HBGS: House-Brackmann Grading System, SBGS: Sunnybrook Grading System

points and the HBGS, SBGS, and FDI scores, and the internal consistency were evaluated by calculating the Spearman's Rho Correlation coefficient ( $r$ value). Cronbach's $\alpha$ coefficient was calculated to evaluate the internal consistency of the items in the FaCE scale. A Cronbach $\alpha$ worth of $>0.8$ is recommended but $\alpha>0.7$ is acceptable (21). The test-re test reliability was analyzed with the Intraclass Correlation Coefficient (ICC). A worth of $p<0.05$ was admitted as statistically significant.

\section{RESULTS}

\section{Validation}

This prospective study, conducted between November 2019 and June 2020, included a total of 37 patients comprising 13 (35\%) females and 24 (65\%) males, with an average age of $47.35 \pm 16.1$ years (range, 18-70 years). All the patients completed the Turkish versions of the FaCE and FDI. Unilateral PFP was determined on the right side in 19 (51.4\%) patients and on the left side in 18 (48.6\%). The mean duration of PFP was $85.8 \pm 105.8$ months (range, 3-480 months). The most common etiological cause was acoustic neuroma at the rate of $27 \%$. The mean SBGS points were determined to be $35.84 \pm 18.8$ (median:30) and the mean HBGS points to be $4.16 \pm 1.19$ (median:5) (Table 1).

The baseline (D0) and $7^{\text {th }}$ day (D7) total and sub-domain scores of the FaCE and the FDI scores of the patients are shown in Table 2.

\section{Internal consistency and reliability}

Internal consistency was tested with the Cronbach $\alpha$ coefficient, which was calculated to show an excellent value at 0.828 . Points in the range of 0.67 to 0.81 were calculated for the subdomains of the FaCE scale. The test-re test reliability was shown with ICC values ranging from 0.51 to 0.95 (Table 3).
Correlations between the FaCE scale and the HBGS, SBGS, and FDI points were calculated with the Spearman coefficient. A good correlation was determined between FaCE and the HBGS and SBGS points ( $r=-0.51, r=0.65$, respectively). The correlation with

Table 2: Facial Clinimetric Evaluation (FaCE) scale and Facial Disability Index (FDI) scores.

\begin{tabular}{|c|c|c|c|c|}
\hline $\mathrm{DO}(\mathrm{n}=37)$ & Mean & SD & Median & Range \\
\hline \multicolumn{5}{|l|}{ FDI } \\
\hline Physical function & 68.11 & 19.38 & 70 & $30-95$ \\
\hline Social/Well-being function & 74.59 & 19.65 & 80 & $16-100$ \\
\hline \multicolumn{5}{|l|}{ FaCE Scale } \\
\hline Facial movement & 21.82 & 24.71 & 8.3 & $0-91.6$ \\
\hline Facial comfort & 66.87 & 26.1 & 58.3 & $0-100$ \\
\hline Oral function & 68.58 & 29.41 & 75 & $0-100$ \\
\hline Eye comfort & 51.12 & 35.20 & 50 & $0-100$ \\
\hline Lacrimal control & 66.35 & 32.65 & 75 & $0-100$ \\
\hline Social function & 77.03 & 24.65 & 87.5 & $6.25-100$ \\
\hline Total & 58.97 & 17.22 & 60 & $16.6-95$ \\
\hline \multicolumn{5}{|l|}{ D7 $(n=37)$} \\
\hline \multicolumn{5}{|l|}{ FaCE Scale } \\
\hline Facial movement & 28.11 & 23.11 & 16.6 & $0-83.3$ \\
\hline Facial comfort & 63.93 & 24.13 & 58.3 & $25-100$ \\
\hline Oral function & 66.22 & 29.59 & 62.5 & $0-100$ \\
\hline Eye comfort & 52.70 & 35.00 & 50 & $0-100$ \\
\hline Lacrimal control & 65.74 & 32.06 & 75 & $0-100$ \\
\hline Social function & 81.42 & 22.70 & 87.5 & $12.5-100$ \\
\hline Total & 60.56 & 17.43 & 60 & $15-96.6$ \\
\hline
\end{tabular}

SD: Standard Deviation, D0: Day 0, D7: Day 7 
Table 3: Test-Re test Reliability and Internal Consistency of the FaCE scale.

\begin{tabular}{lcccc}
\hline & \multicolumn{2}{c}{ Internal consistency Cronbach's $\alpha$} & \multicolumn{2}{c}{ Test - Retest } \\
\cline { 2 - 5 } & Test & Retest & ICC & $0.903-0.974$ \\
\hline Total & 0.828 & 0.836 & 0.950 & $0.719-0.931$ \\
Facial movement score & 0.800 & 0.709 & 0.862 & $0.817-0.951$ \\
Facial comfort score & 0.812 & 0.775 & 0.905 & $0.909-0.976$ \\
Oral function score & 0.673 & 0.726 & 0.953 & $0.881-0.968$ \\
Eye comfort score & 0.672 & 0.671 & 0.939 & $0.054-0.754$ \\
Lacrimal control & $*$ & $*$ & 0.519 & 0.816 \\
Social function & 0.769 & 0.832 & 0.905 \\
\hline
\end{tabular}

$\mathrm{Cl}$ : confidence interval, ICC: intraclass correlation coefficient, *Cronbach's $\alpha$ could not be calculated for only one item on the scale

Table 4: Correlations between the FaCE scale scores and the House-Brackmann, Sunnybrook, and FDI scores.

\begin{tabular}{lcccc}
\hline FaCE & $\begin{array}{c}\text { HBGS } \\
(\mathbf{n}=37)\end{array}$ & $\begin{array}{c}\text { SBGS } \\
(\mathbf{n}=37)\end{array}$ & $\begin{array}{c}\text { FDI Physical function } \\
(\mathbf{n}=\mathbf{3 7})\end{array}$ & $\begin{array}{c}\text { FDI Social/Well-being function } \\
(\mathbf{n}=\mathbf{3 7})\end{array}$ \\
\hline Facial movement score & $-0.612^{* *}$ & $0.508^{* *}$ & 0.287 & $0.410^{*}$ \\
Facial comfort score & -0.274 & 0.293 & $0.455^{* *}$ & 0.310 \\
Oral function score & $-0.461^{* *}$ & $0.613^{* *}$ & $0.839^{* *}$ & $0.428^{* *}$ \\
Eye comfort score & -0.242 & 0.291 & $0.369^{*}$ & $0.373^{*}$ \\
Lacrimal control & -0.116 & 0.225 & 0.251 & -0.066 \\
Social function & -0.242 & $0.410^{*}$ & $0.379^{*}$ & $0.696^{* *}$ \\
Total & $-0.510^{* *}$ & $0.651^{* *}$ & $0.692^{* *}$ & $0.663^{* *}$ \\
\hline
\end{tabular}

${ }^{*} p<0.05, * * p<0.01$

HBGS was negative due to the design of the HBGS. The facial movement score of the FaCE scale showed the highest correlation with HBGS ( $r=-0.61)$. The SBGS had the highest correlation with the oral function score of the FaCE scale $(r=0.61)$. There was a good correlation between the FaCE scale and the social/ well-being function and physical function of the FDI ( $r=0.66$, $r=0.69$, respectively). The FDI physical function had the highest correlation with the oral function score of the FaCE $(r=0.83)$ and the FDI social/well-being function had the highest correlation with the social function score of the FaCE ( $r=0.69)$ (Table 4).

\section{DISCUSSION}

This study was conducted for validation of the FaCE scale, the Turkish version of which was created. The translation into Turkish and inter-cultural adaptation was performed in accordance with international literature (19). No difficulties were encountered in the translation and adaptation process. As far as we know, our study is the first study to have translated the FaCE scale into Turkish and provided validation. Patients with temporary PFP, which can recover rapidly, primarily Bell's palsy, were excluded from the study.

PFP has a negative effect on the psychosocial status of patients, communication, and quality of life. Patients with severe PFP may show more severe physical disability, but may not experience more social disabilities or psychological problems (22). The effect of PFP on the QoL of the patient cannot be estimated by the level of the facial paralysis (23-25). In a systematic examination of the results of patient-based scales, Ho et al reported that the inclusion and exclusion criteria of 3 scales corresponded specifically to facial paralysis. Of these, the FaCE scale and FDI were accepted as valid for peripheral facial paralysis patients, and the FaCe scale was seen to meet all psychometric standards (23).

The Turkish FaCE scale had Cronbach $\alpha$ values of 0.828 and 0.836 (test and re test) for internal consistency. These values showed excellent internal consistency, which was in accordance with findings in literature when compared with German, Chinese, Dutch, French, and Spanish versions (11-14, 17). The only item for which Cronbach $\alpha$ could not be calculated was lacrimal control. All the patients completed the questionnaire on D7, so there was no loss to follow-up in the study. The ICC value for the Turkish FaCE scale showed good reliability with sub-domain and total points of 0.95-0.52.

A good correlation was determined between the Turkish FaCE scale and SBGS and HBGS ( $r=0.65, r=-0.510$, respectively). The FaCE scale facial movement score had the highest correlation with HBGS $(r=0.612)$. These results were consistent with the original English FaCE scale results, developed by Khan et al ( $r=0.55, r=0.69$, respectively). There was a good correlation between the facial movement score of the FaCE and the SBGS $(r=0.508)$. However, in contrast to findings in the literature, the highest correlation was seen to be with oral function $(6,12,15)$. 
The correlations between the FaCE scale and the FDI social function and physical function were determined to be at a good level ( $r=0.66, r=0.69$, respectively). The highest correlation was seen between the oral function score of the FaCE scale and the FDI physical function score $(r=0.839)$, which was consistent with the results of the original English version (6). This correlation could be due to the fact that 4 of the 5 questions in the FDI physical function domain are related to oral function (15). The FaCE scale social function score showed the highest correlation with the FDI social function score $(r=0.696)$, consistent with the literature $(6,13-15)$.

The mean values of the total and sub domain scores of the Turkish FaCE scale were determined to be higher compared to values in the literature $(12,13,26)$. The reason for this could be attributed to the long duration of PFP (mean: 85.5 months, range: 3-480 months) and patients accepting their current status as etiologically permanent facial paralysis, which enabled adaptation and better tolerance of the psychosocial effects of PFP.

FaCE is the most widely used and most important of the QoL scales in patients with peripheral facial paralysis. It has also been used for various international academic studies $(9,23$, 27). The FDI only evaluates two areas, the social function and physical function (7), whereas the FaCE scale evaluates a much broader area in which there could be negative effects of PFP (6). Therefore, in addition to QoL evaluation, the FaCE scale is of guidance in determining the problems of the patient. For example, a patient with a low oral function score can be referred to a clinician for precautions to be taken on this subject in the future. The reliable and valid Turkish FaCE scale will fill the gap that has been felt in the Turkish-speaking PFP patient population in respect to the evaluation and follow up of patients and referral to clinicians.

A limitation of this study was the relatively low number of patients in the study population compared to the literature $(6,11-13)$. This was due to the exclusion of patients who could show rapid healing, such as those with Bell's palsy, as this could have created great differences in the scale scores.

\section{CONCLUSION}

The FaCE scale is a patient-based, reliable and valid tool which evaluates quality of life. The Turkish FaCE scale, showing high validity and reliability, can be used for Turkish-speaking patients with facial paralysis. Therefore, this study can be considered to have paved the way for the use of FaCE not only for patient evaluation and follow up but also in Turkish clinical studies.

Acknowledgements: We would like to thank Dr. Richard E. Gliklich for his permission to use the FaCE Scale.

Ethics Committee Approval: The study was approved by the Ethics Working Group for Scale Evaluation of Gazi University (Approval no: 2019-361).

Informed Consent: We obtained permission for this study by interviewing the authors of the English original of the FaCE scale.
Peer-Review: Externally peer-reviewed.

Author Contributions: Conception/Design of Study- A.Y., F.C.E., H.T.; Data Acquisition- A.Y., M.Y.; Data Analysis/Interpretation- A.Y., M.Y.; Drafting Manuscript- A.Y., F.C.E.; Critical Revision of Manuscript- F.C.E., H.T.; Final Approval and Accountability- A.Y., F.C.E., H.T.

Conflict of Interest: Authors declared no conflict of interest.

Financial Disclosure: Authors declared no financial support.

\section{REFERENCES}

1. Owusu JA, Stewart CM, Boahene K. Facial Nerve Paralysis. Med Clin North Am 2018;102(6):1135-43.

2. Lorch M, Teach SJ. Facial nerve palsy: etiology and approach to diagnosis and treatment. Pediatr Emerg Care 2010;26(10):763-9; quiz 70-3.

3. Luijmes RE, Pouwels S, Beurskens CH, Kleiss IJ, Siemann I, et al. Quality of life before and after different treatment modalities in peripheral facial palsy: A systematic review. Laryngoscope 2017;127(5):1044-51.

4. House JW, Brackmann DE. Facial nerve grading system. Otolaryngol Head Neck Surg 1985;93(2):146-7.

5. Ross BG, Fradet G, Nedzelski JM. Development of a sensitive clinical facial grading system. Otolaryngol Head Neck Surg 1996;114(3):380-6.

6. Kahn JB, Gliklich RE, Boyev KP, Stewart MG, Metson RB, et al. Validation of a patient-graded instrument for facial nerve paralysis: the FaCE scale. Laryngoscope 2001;111(3):387-98.

7. VanSwearingen JM, Brach JS. The Facial Disability Index: reliability and validity of a disability assessment instrument for disorders of the facial neuromuscular system. Phys Ther 1996;76(12):1288-98; discussion 98-300.

8. Györi E, Przestrzelski C, Pona I, Hagmann M, Rath T, et al. Quality of life and functional assessment of facial palsy patients: A questionnaire study. Int J Surg 2018;55:92-7.

9. Tavares-Brito J, van Veen MM, Dusseldorp JR, Bahmad F, Jr., Hadlock TA. Facial Palsy-Specific Quality of Life in 920 Patients: Correlation With Clinician-Graded Severity and Predicting Factors. Laryngoscope 2019;129(1):100-4.

10. Bruins TE, van Veen MM, Mooibroek-Leeuwerke T, Werker PMN, Broekstra DC, et al. Association of Socioeconomic, Personality, and Mental Health Factors With Health-Related Quality of Life in Patients With Facial Palsy. JAMA Otolaryngol Head Neck Surg 2020;146(4):331-7.

11. Garcia-Iza L, Chiesa-Estomba CM, Rosell-Romero N, IbargurenEsnal E, Soriano-Reixach M, et al. Translation and Validation of the Facial Clinimetric Evaluation Scale to Spanish. Otolaryngol Head Neck Surg 2020:194599820969622.

12. Barry P, Mancini J, Alshukry A, Salburgo F, Lavieille JP, et al. Validation of French versions of the Facial Disability Index and the Facial Clinimetric Evaluation Scale, specific quality of life scales for peripheral facial palsy patients. Clin Otolaryngol 2019;44(3):31322.

13. Kleiss IJ, Beurskens CH, Stalmeier PF, Ingels KJ, Marres HA. Quality of life assessment in facial palsy: validation of the Dutch Facial Clinimetric Evaluation Scale. Eur Arch Otorhinolaryngol 2015;272(8):2055-61. 
14. Volk GF, Steigerwald F, Vitek P, Finkensieper M, Kreysa $H$, et al. [Facial Disability Index and Facial Clinimetric Evaluation Scale: validation of the German versions]. Laryngorhinootologie 2015;94(3):163-8.

15. Marsk E, Hammarstedt-Nordenvall L, Engström M, Jonsson L, Hultcrantz M. Validation of a Swedish version of the Facial Disability Index (FDI) and the Facial Clinimetric Evaluation (FaCE) scale. Acta Otolaryngol 2013;133(6):662-9.

16. Pavese C, Cecini M, Camerino N, De Silvestri A, Tinelli C, et al. Functional and social limitations after facial palsy: expanded and independent validation of the Italian version of the facial disability index. Phys Ther 2014;94(9):1327-36.

17. Li Y, Jiang $H$, Wang $K$, Feng GD, Ding $X Y$, et al. [Quality of life survey on patients with peripheral facial paralysis by using Chinese version of the FaCE scale]. Zhonghua Er Bi Yan Hou Tou Jing Wai Ke Za Zhi 2013;48(1):11-6

18. Özden F, Karaman ÖN, Tuğay N, Savaş Ö, Sözen T, et al. The reliability and validity of the Turkish version of the Facial Disability Index. Disabil Rehabil 2020:1-10.

19. Guillemin F, Bombardier C, Beaton D. Cross-cultural adaptation of health-related quality of life measures: literature review and proposed guidelines. J Clin Epidemiol 1993;46(12):1417-32.

20. Beaton DE, Bombardier C, Guillemin F, Ferraz MB. Guidelines for the process of cross-cultural adaptation of self-report measures. Spine (Phila Pa 1976) 2000;25(24):3186-91.
21. Field A. Discovering statistics using IBM SPSS statistics: sage; 2013

22. Díaz-Aristizabal $U$, Valdés-Vilches $M$, Fernández-Ferreras $T R$, Calero-Muñoz E, Bienzobas-Allué E, et al. Correlations between impairment, psychological distress, disability, and quality of life in peripheral facial palsy. Neurologia 2019;34(7):423-8.

23. Ho AL, Scott AM, Klassen AF, Cano SJ, Pusic AL, Laeken NV. Measuring quality of life and patient satisfaction in facial paralysis patients: a systematic review of patient-reported outcome measures. Plast Recons Surg 2012;130(1):91-9.

24. Cross T, E. Sheard C, Garrud P, Nikolopoulos TP, O'Donoghue GM. Impact of facial paralysis on patients with acoustic neuroma. Laryngoscope 2000;110(9):1539-42.

25. Lee J, Fung K, Lownie SP, Parnes LS. Assessing impairment and disability of facial paralysis in patients with vestibular schwannoma. Arch Otolaryngol Head Neck Surg 2007;133(1):56-60.

26. Tavares-Brito J, Fonseca ACO, Torres RP, van Veen MM, Greene J, et al. Facial Clinimetric Evaluation Scale and Synkinesis Assessment Questionnaire Translation into Brazilian Portuguese: A Validation Study. Int Arch Otorhinolaryngol 2020;24(1):e24-30.

27. Ng JH, Ngo RY. The use of the facial clinimetric evaluation scale as a patient-based grading system in Bell's palsy. Laryngoscope. 2013;123(5):1256-60. 